\title{
Observations of Simultaneous Sperm Release and Larval Planulation Suggest Reproductive Assurance in the Coral Pocillopora acuta
}

\author{
Hillary A. Smith ${ }^{1 *}$, Aurelie Moya ${ }^{2}$, Neal E. Cantin ${ }^{3}$, Madeleine J. H. van Oppen ${ }^{3,4}$ and \\ Gergely Torda ${ }^{2,3}$
}

${ }^{1}$ College of Science and Engineering, James Cook University, Townsville, QLD, Australia, ${ }^{2}$ ARC Centre of Excellence for Coral Reef Studies, James Cook University, Townsville, QLD, Australia, ${ }^{3}$ Australian Institute of Marine Science, Townsville, QLD, Australia, ${ }^{4}$ School of BioSciences, University of Melbourne, Parkville, VIC, Australia

\section{OPEN ACCESS}

Edited by:

Stefano Goffredo,

University of Bologna, Italy

Reviewed by:

Isabelle Domart-Coulon, Muséum National d'Histoire Naturelle,

France

Emma Mary Gibbin,

École Polytechnique Fédérale

de Lausanne, Switzerland

Robert H. Richmond,

University of Hawaii at Manoa,

United States

Tom Shlesinger,

Tel Aviv University, Israel

*Correspondence: Hillary A. Smith

hillary.smith@my.jcu.edu.au;

hillary.adele@gmail.com

Specialty section: This article was submitted to

Coral Reef Research,

a section of the journal Frontiers in Marine Science

Received: 07 March 2019 Accepted: 12 June 2019

Published: 26 June 2019

Citation:

Smith HA, Moya A, Cantin NE, van Oppen MJH and Torda G (2019) Observations of Simultaneous Sperm Release and Larval Planulation

Suggest Reproductive Assurance in the Coral Pocillopora acuta.

Front. Mar. Sci. 6:362.

doi: 10.3389/fmars.2019.00362
Despite being an extensively studied group of corals, the reproductive biology of the scleractinian genus Pocillopora remains a mystery. Pocillopora acuta has been proposed to exhibit a mixed reproductive mode, sexually producing gametes (sperm and eggs) and asexually brooding larvae simultaneously within a single colony. Here, we report observations of night-time spawning of sperm during the peak monthly larval release period. We offer a new hypothesis for the regulation of sexual and asexual reproduction in the species and posit that sexual reproduction may occur more often than previously suggested. However, the success of internal oocyte fertilization and subsequent zygote development is dependent on sperm making contact with a fertile colony. We hypothesize that asexual development of larvae occurs when sperm is absent, but more extensive genetic, genomic, and histological data are required to determine the pathway by which unfertilized oocytes may develop. We also propose that this mixed mode of reproduction is an adaptation to mating failure, common in sessile marine invertebrates. The reproductive assurance enjoyed by the species may therefore be the key to its ecological and evolutionary persistence.

Keywords: spawning, reproductive assurance, coral, Pocillopora, reproduction

\section{INTRODUCTION}

The coral Pocillopora acuta (Lamarck, 1816), formerly synonymised under Pocillopora damicornis (Linnaeus, 1758) (Schmidt-Roach et al., 2014b), is one of the most extensively studied corals in the world. Despite decades of intensive research, the origin of larvae and the mechanisms controlling larval development remain a mystery. The hermaphroditic species is thought to have a mixed reproductive strategy across its Indo-Pacific range, employing both gamete spawning and (presumably) asexual brooding, with the dominance of each strategy varying by geographic location (Supplementary Table 1). Brooded larvae, thought to be asexually produced, are released monthly in summer and synchronized to the lunar cycle (Stoddart, 1983; Jokiel et al., 1985; Tanner, 1996; Whitaker, 2006; Combosch and Vollmer, 2013). Polyps simultaneously engage in gametogenesis (Harriott, 1983; Stoddart and Black, 1985; Yeoh and Dai, 2010), but the fate of gametes was, until recently, unknown. Broadcast spawning had previously been inferred from multiple observations of the disappearance of mature gametes from histological sections (Muir, 1984; Stoddart and Black, 1985; Ward, 1992; Permata et al., 2000). Daytime spawning of sperm was observed following the full 
moon in the austral summer in 2011 on the Great Barrier Reef (GBR; Schmidt-Roach et al., 2012), in June 2013 in Hawai'i (Schmidt-Roach et al., 2014a) and in December 2015 on the GBR (G. Torda, pers. obs.). Daytime spawning is characteristic of other members in the genus Pocillopora (Schmidt-Roach et al., 2014a and references therein), however, the scarcity of spawning observations in $P$. acuta suggests that it is a rather rare phenomenon.

Despite the overarching acceptance that $P$. acuta releases almost exclusively apomictic parthenogenetic (i.e., clonal, asexually produced; Figure 1) planula larvae, with additional infrequent broadcast spawning of gametes (Stoddart, 1983; Ward, 1992; Schmidt-Roach et al., 2012), population genetic research on Pocillopora species has led to contradicting and complex interpretations of the coral's life history. Western Australian populations of $P$. damicornis sensu lato maintain highly clonal populations, but still show evidence of some sexual recruitment (Stoddart, 1984a,b; Whitaker, 2006). On the GBR, some populations are primarily sexually derived (Ayre et al., 1997; Ayre and Miller, 2004; Sherman et al., 2006), while others are predominantly clonal (Cantin, unpublished). In addition, strong genetic differentiation at fine spatial scales contrasts with genetic panmixia at regional scales (Benzie et al., 1995; Ayre et al., 1997; Ayre and Hughes, 2000; Torda et al., 2013), a paradox that has long puzzled researchers. These conflicting results have historically been explained as reproductive plasticity, with the prevalence of sexual or asexual recruitment varying by local environmental conditions and geographic location (Veron and Pichon, 1976).

Here, we report night-time sperm spawning of P. acuta, collected in the central GBR and held in aquaria under artificial light mimicking natural lunar and solar light patterns (i.e., periodicity and intensity). We offer a new interpretation of bewildering past results, and present an alternative hypothesis which may help to explain controversies over different proposed life histories.

\section{OBSERVATIONS AND DISCUSSION}

Forty-nine colonies of $P$. acuta were collected from Davies Reef in November 2016 under permit number G12/35236.1 issued by the Great Barrier Reef Marine Park Authority to the Australian Institute of Marine Science (AIMS). The corals were transferred to the AIMS National Sea Simulator and were placed in individual aquaria equipped with larval capture devices. Colonies were observed daily from December 2016 to April 2017, and the number of planula larvae released were counted under a microscope at midday each day. Planulation consistently commenced 3-4 days following the new moon and offspring production peaked between 5 and 9 days after the new moon each month, with a clear peak release in December (Supplementary Figure 1). The five most productive colonies were isolated prior to the new moon on January 28, 2017. At the height of the monthly planulation on February 4, 2017 (Supplementary Figure 1), highly inconspicuous streaks of sperm were observed around $P$. acuta colonies, visible only when a red light source was placed directly behind the colonies (Figure 2). Sperm oozed three times between 1 am and 3 am, for approximately $10 \mathrm{~min}$ each time, from all five colonies isolated individually in $60 \mathrm{~L}$ observation aquaria. The quantity of the sperm was too low to cloud the water in the aquaria. The highly cryptic nature of sperm spawning in this species suggests that this phenomenon may have been overlooked in the past, and that sperm release may be more frequent in $P$. acuta than previously thought. While recent taxonomic reclassification (SchmidtRoach et al., 2014b) may help to unravel some contradictory results of past studies, the close phylogenetic relationship between $P$. damicornis and $P$. acuta suggests that both species may possess this unique reproductive feature. Indeed, other species in the same family (including the genera Seriatopora and Stylophora) are sexually reproducing brooders (Ayre and Resing, 1986; Rinkevich and Loya, 1987); thus it would be unexpected for other pocilloporids to lack the ability for sexual recombination.

Concurrent sperm release alongside peak planula release has important implications for understanding the species' reproductive biology and population genetics. Despite conflicting population level studies, it has been demonstrated that $P$. damicornis sensu lato larvae develop directly from eggs (Permata et al., 2000) not from somatic budding. While somatic budding has been proposed (Muir, 1984), and some genetic evidence lends support to the theory (i.e., "sexual" offspring could actually represent somatic mutations; Yeoh and Dai, 2010; Combosch and Vollmer, 2013), critically there has been no histological evidence of the transition from a somatic bud to a planula larva. It has also been shown that P. damicornis releases both asexually and sexually produced larvae within a single brood in experimental settings (Yeoh and Dai, 2010; Combosch and Vollmer, 2013). It is plausible that isolating colonies in aquaria days prior to the expected date of planulation for larval collection restricts access to conspecific sperm, which may explain variability in detected rates of sexual versus asexual reproduction among previous studies (Szmant-Froelich et al., 1985; Permata et al., 2000). This is in agreement with evidence suggesting that - similar to broadcast spawning coral species - development of planulae from oocytes in brooding corals may occur in as little as 4 days, but can be brooded for weeks prior to release (Szmant-Froelich et al., 1985; Permata et al., 2000). We propose that when sperm is absent, $P$. acuta produces parthenogenic offspring through automixis, diploidization of oocytes, or restitutional meiosis (Figure 1); alternately, when sperm is present, $P$. acuta is able to reproduce sexually (Figure 3) - a strategy consistent with the reproductive assurance hypothesis. Indeed, eggs of some coral species contain sperm attractant molecules, and this could explain why sexual reproduction is favored in the presence of sperm (Coll et al., 1994; Hussain et al., 2016). Our hypothesis would explain why Combosch and Vollmer (2013) observed a greater proportion of sexually produced larvae at the beginning of the planulation event - colonies were isolated the day prior to planulation, and thus eggs may have already been fertilized by other colonies in the aquaria. The oocytes that had not been exposed to sperm developed through a parthenogenic pathway. Future research should test this hypothesis experimentally. Importantly, it 


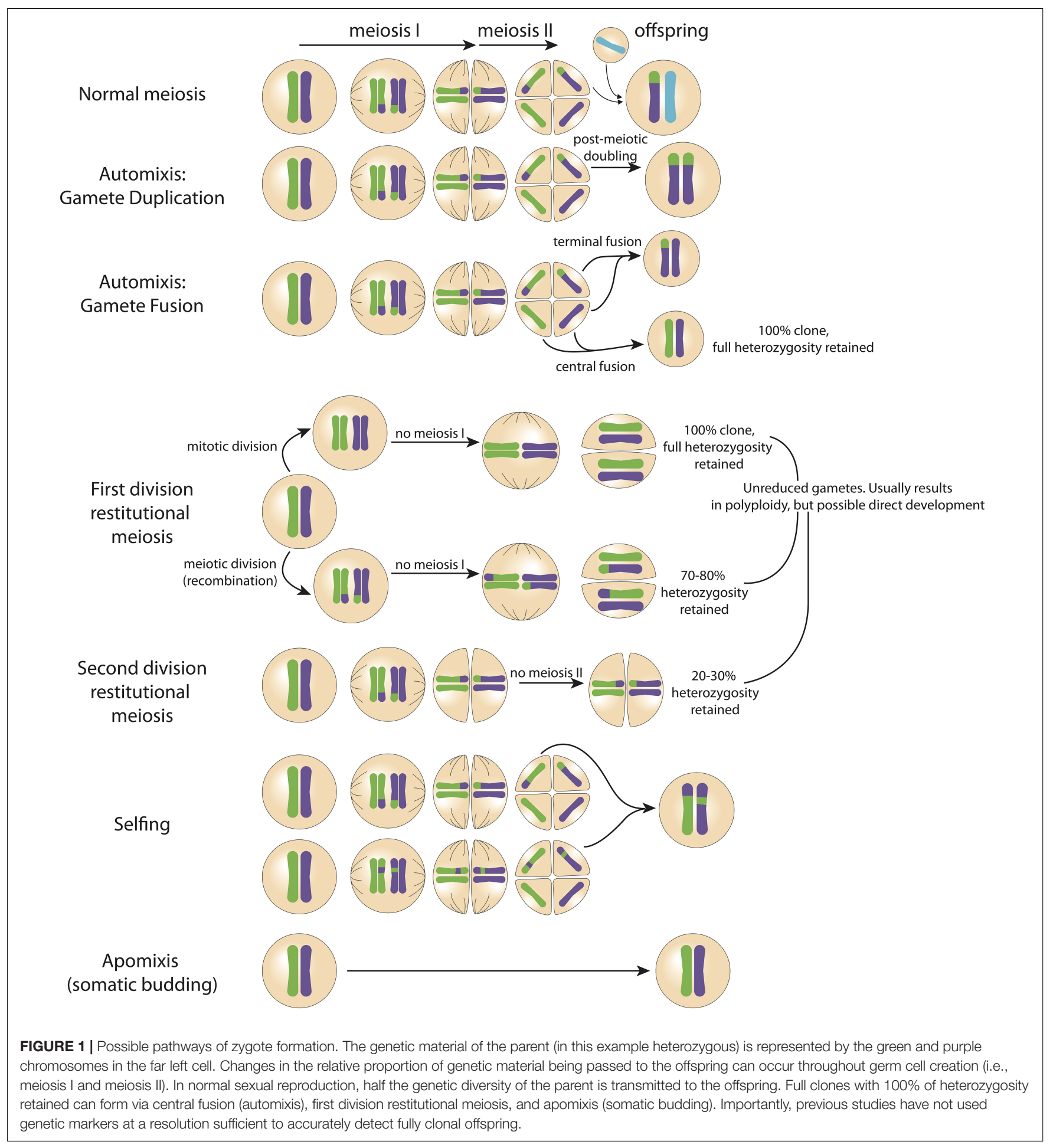

should be noted that the low-resolution genetic markers (i.e., microsatellites, allozymes) used in previous studies may not be powerful enough to detect $100 \%$ clonality, and therefore apomixis (somatic budding) may have been falsely concluded in other words, analyses based on low resolution genetic markers will deduce clonality where there are actually genetic differences. Our hypothesis neither promotes nor rules out the possibility for apomixis. Next-generation sequencing provides the technology to better assess if apomictic parthenogenesis, automictic parthenogenesis, restitutional meiosis, or sexual reproduction (Figure 1) is reflected in offspring genotypes.

The reproductive assurance hypothesis is well-documented in plants, and posits that selection favors self-fertilization where outbreeding is limited by a scarcity of mates (Darwin, 1876; 


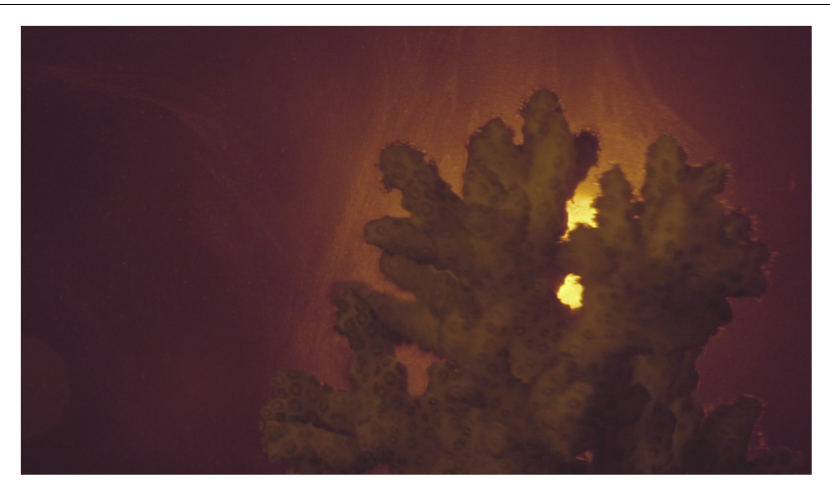

FIGURE 2 | Wisps of sperm were only visible when the red light source was placed directly behind the colony, creating a silhouette. Spawning was observed three times throughout the night during the time of peak planula release. See Video clip in Supplementary Material.

Goodwillie et al., 2005). The hypothesis has rarely been investigated or observed in animals (but see Jarne and Auld, 2006), but selfing has been observed in other pocilloporid corals (Sherman, 2008). Similar to selfing, parthenogenesis liberates sessile organisms such as corals from dependence on population densities required for availability of non-self conspecific sperm.
In low population densities, a mixed-mode of reproduction would be expected to reinforce the benefits of the strategy: reproductive success would still be possible, thus allowing the species to colonize new habitats or rebound from catastrophic events even in the absence of conspecifics (Tsounis and Edmunds, 2016). However, when mates are within the sperm dispersal range, $P$. acuta may potentially use chemical cues such as sperm chemotaxis to attract non-self sperm (Coll et al., 1994; Hussain et al., 2016), and may thus benefit from the advantages of sexual reproduction. The modular nature of corals may also allow for multiple paternity per colony: when in close proximity to multiple mates, each polyp in a colony may be fertilized by a different father. Homogenization of coral samples containing developing larvae from multiple fathers could explain perceived intra-genomic variation (e.g., Maier et al., 2012) or tissue chimerism (e.g., Rinkevich et al., 2016) in past studies. While empirical data on sperm dispersal distances in corals is scarce, one study on a closely related species (Seriatopora hystrix) found that sperm dispersal is quite limited, with over $82 \%$ of mating occurring between colonies within $10 \mathrm{~m}$ of each other (Warner et al., 2016). In addition, self-fertilization is episodic, and multiple paternity is common (Heyward and Babcock, 1986; Warner et al., 2016). These empirical data provide an interesting platform to consider how population density may influence the reproductive strategy of corals.

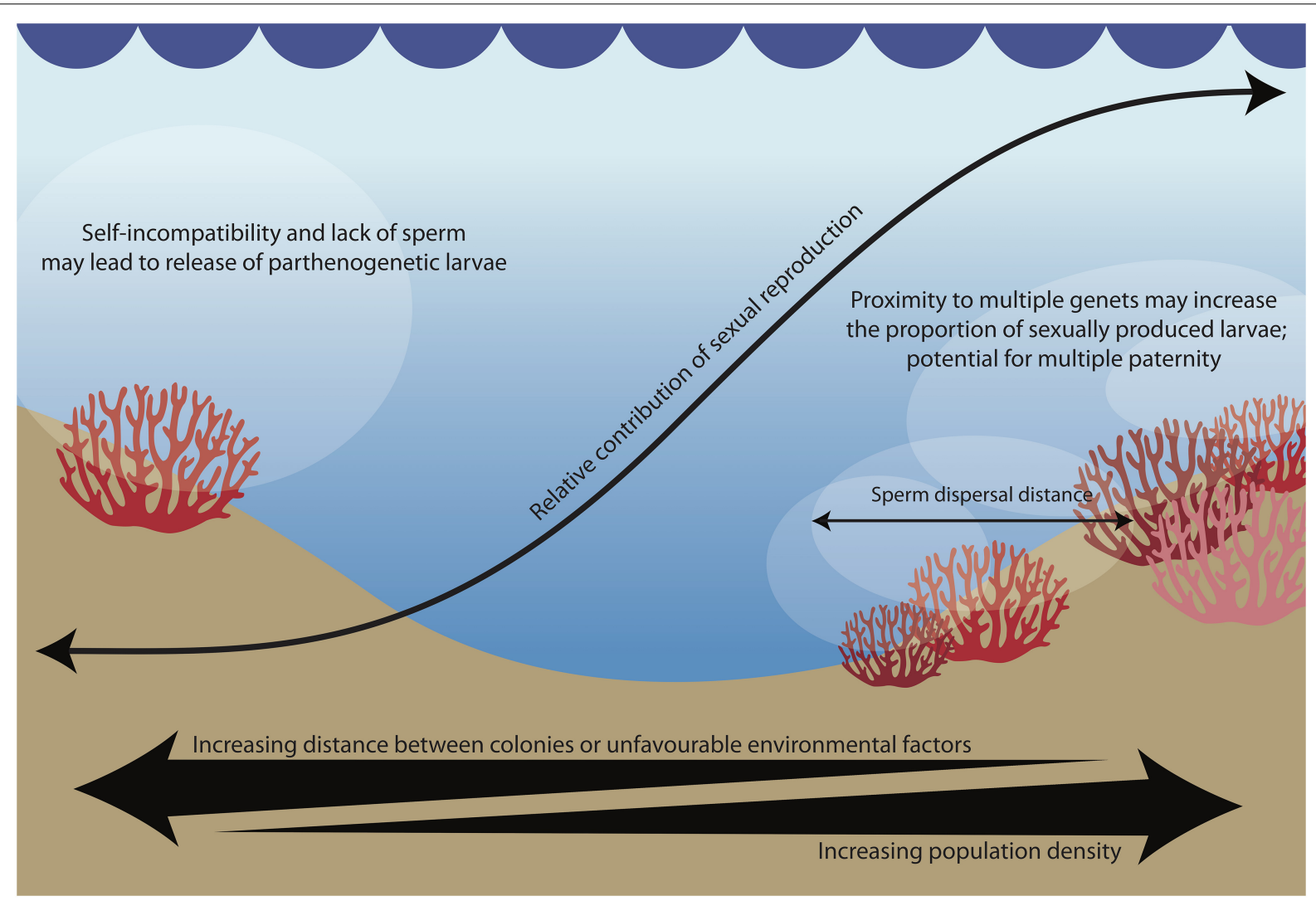

FIGURE 3 | According to our hypothesis, sperm availability increases the proportion of sexually derived offspring and may result in multiple paternity, while mate scarcity leads to the production of parthenogenetic offspring. 
The ability to produce both sexual and asexual offspring may be considered the most advantageous reproductive strategy, achieving a balance between the long-term evolutionary benefits of sexual reproduction and the immediate ecological benefits of asexual reproduction (Hurst and Peck, 1996; Judson and Normark, 1996). Our observation of inconspicuous sperm spawning suggests that reproductive assurance has played a significant role in the evolutionary ecology of Pocillopora species. The mixed reproductive mode has undoubtedly influenced contemporary geographic distributions and population genetic processes. Interestingly, very few brooding corals have displayed evidence of employing a mixed reproductive strategy despite its advantage. It may be worth re-examining other brooding coral species to reveal whether a mixed reproductive mode has evolved but has been overlooked. Many questions remain and our hypothesis has sparked the need for several future studies. Importantly, direct in situ observations of sperm release are needed to validate our observations, and would ideally be recorded and quantified at sites with varying population densities. Second, future work should investigate the genetic composition through whole genome sequencing and/or recombination mapping of larvae derived from isolated versus non-isolated parent colonies to test our hypothesis. Third, more work is needed to determine how often sperm is spawned, timing of oogenesis and spermatogenesis, when fertilization occurs, the role of self-fertilization or self-incompatibility, and the duration of embryonic development. Fourth, theoretical work may wish to consider if the advantage of reproductive assurance is sufficient to outweigh the costs of proliferation of potentially maladapted genotypes (e.g., Darwin, 1876), especially in a changing climate. Fifth, it may be interesting to use single nucleotide polymorphism (SNP) sequencing to determine if sexual reproduction through hybridization with closely related species is more prevalent in small populations due to conspecific mate scarcity. Finally, we suggest that future population genetic surveys should account for a "contact zone" (i.e., spatial distribution of colonies and sperm dispersal distance) to ascertain if the unconsolidated or patchy distribution of conspecifics is associated with a higher proportion of asexual reproduction.

\section{DATA AVAILABILITY}

All datasets generated for this study are included in the manuscript and/or the Supplementary Files.

\section{REFERENCES}

Ayre, D. J., and Hughes, T. P. (2000). Genotypic diversity and gene flow in brooding and spawning corals along the great barrier reef. Aust. Evol. 54, 1590-1605. doi: 10.1111/j.0014-3820.2000.tb00 704.x

Ayre, D. J., Hughes, T. P., and Standish, R. J. (1997). Genetic differentiation, reproductive mode, and gene flow in the brooding coral Pocillopora damicornis along the Great Barrier Reef. Aust. Mar. Ecol. Prog. Ser. 159, 175-187. doi: 10.3354/meps 159175

Ayre, D. J., and Miller, K. J. (2004). Where do clonal coral larvae go? Adult genotypic diversity conflicts with reproductive effort in the brooding coral

\section{ETHICS STATEMENT}

This study was exempt, as research involving corals is not subject to ethics approval. Corals were collected under permit number G14/37318.1 issued by the Great Barrier Reef Marine Park Authority to the Australian Institute of Marine Science (AIMS).

\section{AUTHOR CONTRIBUTIONS}

NC collected the corals. GT and HS maintained the corals in aquaria and GT collected the video observations. GT, HS, and NC collected planula count data with the assistance of those listed under Acknowledgments section. HS and GT wrote the first draft of the manuscript. All authors contributed to concept development, manuscript revision, read and approved the final version of the manuscript.

\section{FUNDING}

This work was supported by the Paul G. Allen Family Foundation and was utilized for coral collections and aquarium setup. $\mathrm{MvO}$ acknowledges the Australian Research Council Laureate Fellowship FL180100036.

\section{ACKNOWLEDGMENTS}

We thank the BBC Stargazing Live film crew - Carina Thomas, Alastair Duncan, Paul Walker, Thomas David, and Greg Quicke - for the footage and photos used in this publication. We gratefully acknowledge the staff of the Australian Institute of Marine Science's National Sea Simulator for assisting with the husbandry of our corals and to Katarina Damjanovic, Sophie Stephenson, and Carine Lefèvre for help in counting planula larvae.

\section{SUPPLEMENTARY MATERIAL}

The Supplementary Material for this article can be found online at: https://www.frontiersin.org/articles/10.3389/fmars. 2019.00362/full\#supplementary-material

Pocillopora damicornis. Mar. Ecol. Prog. Ser. 277, 95-105. doi: 10.3354/ meps 277095

Ayre, D. J., and Resing, J. M. (1986). Sexual and asexual production of planulae in reef corals. Mar. Biol. 90, 187-190. doi: 10.2307/1541201

Benzie, J. A. H., Haskell, A., and Lehman, H. (1995). Variation in the genetic composition of coral (Pocillopora damicornis and Acropora palifera) populations from different reef habitats. Mar. Biol. 121, 731-739. doi: 10.1007/ bf00349309

Coll, J. C., Bowden, B. F., Meehan, G. V., Konig, G. M., Carroll, A. R., Tapiolas, D. M., et al. (1994). Chemical aspects of mass spawning in corals. I. Spermattractant molecules in the eggs of the scleractinian coral Montipora digitata. Mar. Biol. 118, 177-182. doi: 10.1007/bf00349783 
Combosch, D. J., and Vollmer, S. V. (2013). Mixed asexual and sexual reproduction in the Indo-Pacific reef coral Pocillopora damicornis. Ecol. Evol. 3, 3379-3387. doi: $10.1002 /$ ece 3.721

Darwin, C. (1876). The Effects of Cross and Self Fertilisation in the Vegetable Kingdom. London: John Murray.

Goodwillie, C., Kalisz, S., and Eckert, C. G. (2005). The evolutionary enigma of mixed mating systems in plants: occurrence, theoretical explanations, and empirical evidence. Annu. Rev. Ecol. Evol. Syst. 36, 47-79. doi: 10.1146/ annurev.ecolsys.36.091704.175539

Harriott, V. J. (1983). Reproductive seasonality, settlement, and postsettlement mortality of Pocillopora damicornis (Linnaeus), at Lizard Island, Great Barrier Reef. Coral Reefs 2, 151-157. doi: 10.1007/bf0033 6721

Heyward, A. J., and Babcock, R. C. (1986). Self- and cross-fertilization in scleractinian corals. Mar. Biol. 90, 191-195. doi: 10.1007/bf00569127

Hurst, L. D., and Peck, J. R. (1996). Recent advances in understanding of the evolution and maintenance of sex. Trends Ecol. Evol. 11, 46-52. doi: 10.1016/ 0169-5347(96)81041-X

Hussain, Y. H., Guasto, J. S., Zimmer, R. K., Stocker, R., and Riffell, J. A. (2016). Sperm chemotaxis promotes individual fertilization success in sea urchins. J. Exp. Biol. 219(Pt 10), 1458-1466. doi: 10.1242/jeb.13 4924

Jarne, P., and Auld, J. R. (2006). Animals mix it up too: the distribution of self-fertilization among hermaphroditic animals. Evol. Int. J. Org. Evol. 60, 1816-1824. doi: 10.1111/j.0014-3820.2006.tb00525.x

Jokiel, P. L., Ito, R. Y., and Liu, P. M. (1985). Night irradiance and synchronization of lunar release of planula larvae in the reef coral Pocillopora damicornis. Mar. Biol. 88, 167-174. doi: 10.1007/bf00397164

Judson, O. P., and Normark, B. B. (1996). Ancient asexual scandals. Trends Ecol. Evol. 11, 41-46. doi: 10.1016/0169-5347(96)81040-8

Maier, E., Buckenmaier, A., Tollrian, R., and Nürnberger, B. (2012). Intracolonial genetic variation in the scleractinian coral Seriatopora hystrix. Coral Reefs 31, 505-517. doi: 10.1007/s00338-011-0857-9

Muir, P. R. (1984). Periodicity and Asexual Planulae Production in Pocillopora damicornis. Townsville: James Cook University.

Permata, W. D., Kinzie, R. A., and Hidaka, M. (2000). Histological studies on the origin of planulae of the coral Pocillopora damicornis. Mar. Ecol. Prog. Ser. 200, 191-200. doi: 10.3354/meps200191

Rinkevich, B., and Loya, Y. (1987). Variability in the pattern of sexual reproduction of the coral Stylophora pistillata at eilat, red sea: a long-term study. Biol. Bull. 173, 335-344. doi: 10.2307/1541546

Rinkevich, B., Shaish, L., Douek, J., and Ben-Shlomo, R. (2016). Venturing in coral larval chimerism: a compact functional domain with fostered genotypic diversity. Sci. Rep. 6:19493. doi: 10.1038/srep19493

Schmidt-Roach, S., Johnston, E., Fontana, S., Jury, C. P., and Forsman, Z. (2014a). Daytime spawning of Pocillopora species in Kaneohe Bay, Hawai'i. Galaxea J. Coral Reef Stud. 16, 11-12. doi: 10.3755/galaxea. 16.11

Schmidt-Roach, S., Miller, K. J., Lundgren, P., and Andreakis, N. (2014b). With eyes wide open: a revision of species within and closely related to the Pocillopora damicornis species complex (Scleractinia; Pocilloporidae) using morphology and genetics. Zool. J. Linn. Soc. 170, 1-33. doi: 10.1111/zoj.12092

Schmidt-Roach, S., Miller, K. J., Woolsey, E., Gerlach, G., and Baird, A. H. (2012). Broadcast spawning by Pocillopora species on the great barrier reef. PLoS One 7:e50847. doi: 10.1371/journal.pone.0050847
Sherman, C. D. H. (2008). Mating system variation in the hermaphroditic brooding coral, Seriatopora hystrix. Heredity 100, 296-303. doi: 10.1038/sj.hdy.680 1076

Sherman, C. D. H., Ayre, D. J., and Miller, K. J. (2006). Asexual reproduction does not produce clonal populations of the brooding coral Pocillopora damicornis on the great barrier reef. Aust. Coral Reefs 25, 7-18. doi: 10.1007/s00338-0050053-x

Stoddart, J. A. (1983). Asexual production of planulae in the coral Pocillopora damicornis. Mar. Biol. 76, 279-284. doi: 10.1007/bf00393029

Stoddart, J. A. (1984a). Genetic differentiation amongst populations of the coral Pocillopora damicornis off Southwestern Australia. Coral Reefs 3, 149-156. doi: 10.1007/bf00301959

Stoddart, J. A. (1984b). Genetical structure within populations of the coral Pocillopora damicornis. Mar. Biol. 81, 19-30. doi: 10.1007/bf00397621

Stoddart, J. A., and Black, R. (1985). Cycles of gametogenesis and planulation in the coral Pocillopora damicornis. Mar. Ecol. Prog. Ser. 23, 153-164. doi: 10.3354/meps023153

Szmant-Froelich, A., Reutter, M., and Riggs, L. (1985). Sexual reproduction of Favia fragum (Esper): lunar patterns of gametogenesis, embryogenesis and planulation in Puerto Rico. Bull. Mar. Sci. 37, 880-892.

Tanner, J. E. (1996). Seasonality and lunar periodicity in the reproduction of Pocilloporid corals. Coral Reefs 15, 59-66. doi: 10.1007/s00338005 0028

Torda, G., Lundgren, P., Willis, B. L., and Oppen, M. J. H. (2013). Revisiting the connectivity puzzle of the common coral Pocillopora damicornis. Mol. Ecol. 22, 5805-5820. doi: $10.1111 / \mathrm{mec} .12540$

Tsounis, G., and Edmunds, P. J. (2016). The potential for self-seeding by the coral Pocillopora spp. in Moorea, French Polynesia. PeerJ 4:e2544. doi: 10.7717/peerj. 2544

Veron, J. E. N., and Pichon, M. (1976). Scleractinia of Eastern Australia. Canberra: Australian Govt. Pub. Service.

Ward, S. (1992). Evidence for broadcast spawning as well as brooding in the scleractinian coral Pocillopora damicornis. Mar. Biol. 112, 641-646. doi: 10. 1007/bf00346182

Warner, P. A., Willis, B. L., and van Oppen, M. J. H. (2016). Sperm dispersal distances estimated by parentage analysis in a brooding scleractinian coral. Mol. Ecol. 25, 1398-1415. doi: 10.1111/mec.13553

Whitaker, K. (2006). Genetic evidence for mixed modes of reproduction in the coral Pocillopora damicornis and its effect on population structure. Mar. Ecol. Prog. Ser. 306, 115-124. doi: 10.3354/meps306115

Yeoh, S.-R., and Dai, C.-F. (2010). The production of sexual and asexual larvae within single broods of the scleractinian coral, Pocillopora damicornis. Mar. Biol. 157, 351-359. doi: 10.1007/s00227-009-1322-y

Conflict of Interest Statement: The authors declare that the research was conducted in the absence of any commercial or financial relationships that could be construed as a potential conflict of interest.

Copyright (C) 2019 Smith, Moya, Cantin, van Oppen and Torda. This is an openaccess article distributed under the terms of the Creative Commons Attribution License (CC BY). The use, distribution or reproduction in other forums is permitted, provided the original author(s) and the copyright owner(s) are credited and that the original publication in this journal is cited, in accordance with accepted academic practice. No use, distribution or reproduction is permitted which does not comply with these terms. 